\title{
FENIKS W LITERATURZE WCZESNOCHRZEŚCIJAŃSKIEJ
}

Feniks, cudowny ptak mityczny wschodniego pochodzenia, lecacy przez 500 lat ku Zachodowi do intasta Heliopolis z Ind11 lub najczóściej z Arabil, poirstajacy na nowo z własnych popiołów po spaloniu slę na oltarzu w świątyni Słońca 1 powracajacy do wachodniej ojczyzny znany starej poezji sanskryckiej, religijnym tekstom ogipskim oraz pisarzom greckin 1 rzymskim ${ }^{1}$, symbol słońca 1 bardzo długiego okresu u Egipcjan, a apoteozy u Rzymian w okresio cesarstwa, pprowadzony zostal po raz pierwszy do literatury chrześcijańskiej przez Klemensa lzyinsklego jako symbol nowych 1 dei.

W swo1m I Liście do Koryntian ${ }^{2}$ Biskup Rzymu zaleca chrześciJanom kontemplować przedziwny znak ukazujący się na Wschodzie licach Arabil w postaci ptaka, zwanego foniksom, który jest wspaniala obletnicq 1 zapowiedzia wskrzeszenta przez stwórce wszystkich, którzy Mu wiernie słuzyli 1 zyli światoblimie w nadziel płynqcej z dobrej wiary. Klemens nazywa go jedynym ptakiem w owo1m rodzaju. Jako tak1 zyje on 500 lat. Pod koniec swego zycla kładzie gie do gniazda uwitego $z$ gałazek kadzidła 1 umiera. $Z$ jego rozkładajacego clała lęgnie sie robak, który karmi sie resztkami gnijących szczatków zinarlego ojca, i jako pisklę obrasta potem piórami. Kiedy zá podrośnte, bierze gniazulo z kośćl swego ojca 1 leci z Arabil do miasta Heliopolis w Eglpcie ${ }^{3}$. Przylatuje tam za dnia 1 w obecnośc1 wszyst-

1 Por, M.F. Mic Donald, Phoenix, New Catholic Encyclopedia, XI 326;

Por. takie J.strzygowski, Der Bilderkreis des griecilschen Phys1olósus, Leipzig 1399; J. Hubaux - M.Leroy, Le mythe du Phén1x dans les littératures grecque et latin, Paris 1939; A.Rusch. Photnix, RE XX 1,414-423; E.Josi, Fenice, ECat Y 1151-1152.

2 Clemens Romanus, Epistola $I$ ad Corinthios 25, SCh 167, 142-144, POK 1, 131-132.

3 Tradycyjng wiadomośc o przylocie ptaka Pentksa do Hellopolis $z$ arabil podaje po raz plerwsy w literaturze greckiej llorodot /Historiae II 73/, a po nim Tacyt /Annales VI 28/ 1 PIInIusz /Historiae naturalis X 2; "nobllem Arabiao phoenicem"/. 2a arabskim pochodzentem feniksa opowiedzlaz sio równiez Tertulian Do rosurroctiono mortuorum $13,2-4, \operatorname{CC} 2,936 /$. Według zas napisanes ok. 200 r. po Chr. koraplacji grecklej "Physiologus"/por. Strzygo- 
kioh Jego mieszkańców składa je na ołtarzu Słońca 1 odlatuje. Miejscoml kepłani siegaja wtedy do roczników, z których dowiaduja sie. ze ptals ten przyleciał po upływie 500 lat 4

Plsarze chrześcijańscy po Klemensie Rzymskim porołuja sle na to opowladanie o Pentksie w prytaczaniu dowodów na nieśmiertelnoś duszy ludzkiej. Tak, np. dla Tertuliana 1 Komodiana ${ }^{5}$, jest on symbolen zmartwychwstania.

T e r u 11 a $n$ w swolm dogmatyczno-polemicznym plómie "De resurrectione mortuorum broniąc przeoiw gnostykom prawdy o zmartmychwstaniu /resurrectio/ ludzkiego clała posłuzyz sie opowiadaniem - Teniks1e jako bardzo mocnym dowodem ${ }^{6}$ : "accipe plenissimam atque firmissimam hulus spei specimen". Miaz on wówczas na mýll tego osobliwego ptaka ze Wschodu, słynnego bez rątpienla dzięk1 swej nadznyczajnośc1 /de singularitate ramosum/, a jeśl1 chodzi o przyszłośc * ogóle stanowi on przedziwny znak /de posteritate monstruosum/, poniewaz odnawia sie wtedy, gdy grzebie siebie samego z ochota/qui semetipsum lubenter lunerans renovat/, odchodzi z miejsca urodzenia

wsk1, dz.cyt. 19/ Teniks miał pochodzić z Indi1.

4 Pịkzośd pisarzy starozytnyoh podaje liczbę 500 lat 1dqo za Herodotem /II 73/, uwaźanym za główne źródło szczegółów opowiadania 0 feniksie literaturze greckiej. Podobnie Tacyt /Annales VI 28/ stwierdza, ze najbirdziej rozpowszechniona tradycja odnosimie liozby lat zycia feniksa podaje okres plésetletni, a tyliso niektórzy mó. wit na serio o odstęple tysiac czterysta sześdziesiçciu 1 jednego roku, co jest liczbą Roku Syriuszonego wipcie./Por. Plinius, Historia naturalis X 2: "vivere annis DXL - zyje 540 lat/. Wedzug św1adectwa Hezjoda /Fragmentum 183/, zam1eszczonego u Plutarcha /Do defectu oraculorum XI 415C/ feniks osiaga okres zycia do 97200 lat. Wedrug greckiej kompllacji "Physiologus" Peniks zyje 500 lat.

5 Por. H.Leclercq, Phén1x, DACL XIV/1, 686, choé takiego stwiordzenia teggo autora nie potwierdza analiza śriadectw wymienionyoh autorów.

6 De resurrectione mortuorum $13,2-4$, CC 2,936 . 
przez smierć 1 znowu powraca/natall el ne decedens atque succedens/. staje siê ponownie feniksem tan, gdzle nie było juz nikogo/iterum phoentx, ubd lan nemo/; jest nim ponownie wraśnie ten, którego juz nie było / iterum 1pse, qui non 1am/, choó 1nny, ale $\mathbf{1}$ istocie ten sara/alius 1dem/. W kolejnych pytaniach retorycznych: "Quid expressius atque signatius in hanc causam? aut oul al11 rel tale documentum?" - zawarta jest odpowiedź Tertuliana nostaci sformułowania - sile wyrazu tego znaku, jako mocnego dowodu na zmartwychwstante ludzklego oiała. Powyższy rozumowy dowód zaczerpnięty z opomiadania o feniksie połączył Tertulian z dowodem biblijnym w następujacej formie: "Bóg bowiem mówi przez swoje Pisma: 'I zakwitnie/spraw1edliwy/ Jak palma, 7 /Ps 91,13/, tj, po śmierc1, po pogrzeb1e, abyś wierzył, ze cielesnej substancji mozna ządac takze od wielkiego ognia. Pan oznajmił, ze 'my jesteśmy więcej warci od wielu wróbli', a Jeśli nle jesteśmy rięcej warci od feniksów, to nie jesteśmy niczym wielkim. Lecz czy ludzie raz na zawsze zgina, chod arabskie ptak1 8q pewne zmartwychwstania? ${ }^{8}$

K o m o d 1 a $n$ w swoim apologetycznym poemacie "Carmen apologeticum" wskazuje równiez na przykład, jaki daje ludziom feniks. Podobnie jak on rozmyila nad ponownym powstaniem ze stanu śmiero1, tak 1 ludzie mogiz powstać po pogrzebie dzięki obiotnicy wszechmocnego Boga, który radzi wierzyó bez zastrzeżén wonowne zycie umarłych; chociaz człowiek jest obecnie prochem 1 goze sa jego kosci. tc jednak będzie on klodyś na nowo integralną całościa, a nawet czymó większyn od tego świata ${ }^{9}$.

L a $k$ a $n$ c $f$ u $z$ nap1saz nawet klasyczny poemat o feniksie "De ave Phoenice" składajacy 818 z 85 dystychów elegijnych ${ }^{10}$. Znajuuja się nim takze mý́l1 pogańskie postacl aluzjl do legendy o Factonie /w. 11/, potopie Neukaliona /w. 13 n/ 1 Febie /w. 35, 41,51/. Ojczyznz Feniksa jest wedrug Laktancjusza jalkaś odległa

7 Greck1 wyraz "pholnix" oznacza tez "palme", zwkaszcza "palme daktylow." - Phoen1x dactylitera.

8 De resurrectione mortuorum $13,3-4$, CC 2,936 .

9 Commodianus, Carmen apologeticum 139-145, CSEL 15, 124.

10 Lactantius, Do ave Phoonice, CSEL 27, 135-147; Por. M.C. Pritz Patrick, Lactanti de ave phoenice. Introduction, Text, Transiation and Comentary, Philadelphia 1933. 
kraina szczęścla /locus felix, w. 1/ na Wachodzle, gdzie stol otworea bardzo nielka brana niecznogo nieba / $/ 2 /$. Znajduje sie tan gaj Słońca z wiecznie zlelonyent liśćmi na drzewach /w. 9 n./, którego nie dotknęiy nigdy ogniste płomiente /, $12 /$, ani nie zalały wody deukalioniskiego potopu /w. $13 \mathrm{n} . /$. Nie ma w tym miejscu oskablających chorób, przykrej starośc1 /w. 15/, okrutnej śmierci, zn1ewalaj fcego strachu $/ \pi$. 16/, hanlebnej zbrodni, szalonej ządzy bogactw/w. 17/ albo gniewu czy gwałtownego szału wiodącego do mordu 2 mirosicl /w. 18/; nle ma tez gorzkiego pracza 1 niedostatku / $19 /$, trosk spęuzających sen z oczu 1 dokuczliwego głodu /w. 20/; nie ma taw weale niepozoly 1 burzl1wych wiatrów / $21 /$, zamiec1 śnieznej 1 żadnej chmury nad ziemią/w. 22 n./, ani ulernego deszczu palającego $z$ wysoka $/ \pi$. 24/. W samyn środku tego rajskiego gaju bije czyste źródlo zwane żymym /w. 25/z obfitościa słodkiej wody /w. 26/, która 12 razy w roku co mlesiąc nawadnia cały gaj /w. 33/, glalo wysokle drzewa dostarczaja słodkich orocón nie spadaJ.jcych na ziemie $/ \pi$. 30/. Ten gaj zamieszkuje jedyny ptak fentks "avis unica Phoenix"/w. 31/, ozywiony dzięiki swej śmierci /w. $32 /$ 1 poślelscony waczególny sposób Febowt /w. 33 n./. Z nastaniem jutrzenkd zanurza on swe clało trzykrotnie lub czterokrotnie w ́́w to pale 1 tylez razy pije zywa wode /w. $35 \mathrm{nn} /$. Poten unosi sie w kure, siala na wierzchołku wysoklego drzewa spoglądajac na cały gaj / $6.39 \mathrm{n} . /$. W oczekıraniu na nowy wschód Słońca zaczyna śpiewá przedzimnym głosen melodie świętej pleśn1/w. 45 n./. K1edy zá Feb wyprowadza swo konie na otwarta przestrzeń ol1mpu, wtedy Feniks przyklaskuje mu trzykrotnle uderzajac swymi skrzydzami na znal czc1 dla jego ognistej growy, a potem milknie /w. $51 \mathrm{nn} . /$ klody przezyje juz tysiac lat 1 stanie sle powazny, chcac odrodzony powrócié do minionego wieku, unika zwykłego przyjennego miejsca apoczytiku w gaju /\$. $59 \mathrm{nn} . /$, opuszcza śwlęte miejsca 1 odlatuje tis, gdzle kriluje śmlerć $/ \pi .63$ n./. Kleruje swoj szybki lot do Syri1, klórej sam nadal nazwe Penicjl/w. 65 n./. Tam w ustronnym Raju elada na wierzcholku palmy, zwanej od sieble phoenix /w, 67 nn./. Z pachnzcych gazłzok 1 liscl wije soble gniazdo jako grób /sepulchrum - w. 77/, kladzle sio w na 1 spala po weniecentu ploalent cleplea swego clara: "ginio boriem, aby zyé, ale sam jednak sig stwarza" Nam perit, ut vival, se tamen 1psa creat - $78 /$. $z$ poplozóm epalonego ptaka powstajo nowy peniks /w. 106/, najplerw 
Jako czerw /w. 103/, który potem przekształca sie ponownie /reformatur/w dawna swa postać $/ w$. 105/, nle przyjmując zadnego zmykłego pozywienia, ale zywiq̨c sie niebiańskim nektarem 1 ambrozja $/ w$. 112/ 1 ostagrajac powoli poczatek kw1tnacej młodośc1/w. 115/. Młady feniks odlatuje wtedy z zamiarem powrotu do ojczystego domu $/ w, 116 /$. Przedtem jednak zabiera ze soba resztki wlasnego oiala 1 popiołu z balsamem, mirra $1 \mathrm{kadz} 1 \mathrm{~d}\} \mathrm{em}$, unosi je do Milasta Słońca 1 umieszcza na ołtarzu w świątyni /w. $117 \mathrm{nn}$ /. Wygląd odrodzonego ptaka jest przeplekny, peken prawdziwego majestatu 1 przedziwnej wspaniałośc1 /w. $144 \mathrm{n} . /$. Blasku dodaja mu orgle barw podobnych do jabłek granatowca, dzikiego maku, czerwieni gleby, koloru płowego metalu 1 różanej róży, purpury, teczy, z1elonkawego szmaragdu /w. 125 nn./. Jego duze oczy podobne sa do hlacyntów /w. $137 \mathrm{n} . /$, a na jego głowle lénl promienlsta korona /w. 139 n./. Ten cudowny ptak jest przy tym lekk1 1 szybki, pełen królewskiego p1ękna /w. 149/, rzadko spotykany $/ w$. 152/, jedyny sqoim rodzaju. Kiedy dolec1 do rejonóm czystego powletrza, zaraz wraca 1 urzadza sobie pogrzeb we właściwym dla sleble mlejscu /w. $159 \mathrm{n} . /$, aby znów ourodzić się tak samo po upływie tysiąca lat. Sam Bóg pozwala mu narodzió się z siebie /w. 162/, nie naturalny sposób jak inne zywe istoty. Laktancjusz kończy swój poemat o tym szczęśliwym/w. 161/ ptaku takimt refleksjami moral nymi:

\footnotetext{
"Felix, quae Veneris foedera nulla colit Nors lili Venus est, sola est in morte voluptas: Ut possit nasci, appetit ante mori. Ipsa sibl proles, suus est.pater et suus heres, Nutrix ipsa sui, semper alumna sibi.

Ipsa quider, sed non eadem est, eademque nec ipsa est, Aoternan vitam mortis adepta bono"11.
}

Sa to jak widać refleksje duchowe niẹ tylko chrześcijańskie, ale utrzyıano duchu głǫbokiego ascetyzmu Senek1 1 mistycyzau Apulejusza, plotyna albo Juliana ${ }^{12}$. Alegoria reniksa ma niewatpliwe u Laktancjusza swa inspiracje w stolcyzmie. Smieró bowlem feniksa ogniu jest Jeduoczénie jego narodzentem się. Oglé́ wieczny niszczy wszystko

11 De ave Phoenice 164-170, CSEL 27, 146-147.

12 Loclercq, art.cyt, 684. 
1 ivszystko odnawia - to stoicka nauka o okresach śviata,które kończą

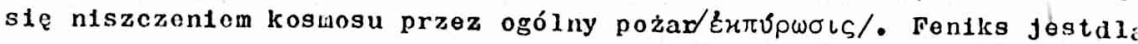
Laktancjusza przede wozystk1m symbolem wlecznego odnawianla ${ }^{13}$; przedstawia bowlem śwlat, który umlera 1 odradza sté na nowo. Moze on być równiez traktawany jako symbol zmartwychwstania, choć sam utwór nie jest wybitnie chrześcijaniskl. Nimo to poemat Lalstancjusza o fon1ks1o 1 traktowante go jako rajskiego ptaka sazklasyczne, a przez owoja wielokształtność 1 alegoryczna kondeneacje daje bogate możlwośc1 interpretacyjno nie tylko w ramach eilozofil stoickiej.

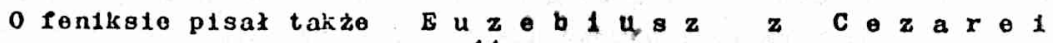
Palostyriskiej " "Vita Constantin1"14. W Czasach Konstantyna W1elklego 1 jego synów, symbol reniksa wykorzystano do monet ujęclu chrzośc1jańskim jako symbol zmartwychistanla Chrystusa. Wskazuje na to porórnanie tego "egipskiego ptaka", jedynego w swoim rodzaju, z zlarnem pszontcy, z którego wyrasta kłos, jakim jost zbawiciel,

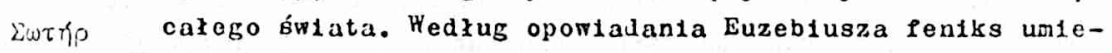
ra na stosie ułozonys z pachnących substanoji 1 składa niejako sieble sanego w oflorze, aby zaraz narodzlé sie ponownie z wzasnych poplołón 1 otrzymać tę samą postać, jaka miał wcześniej na początku. Czyni on to raczej za przykładem swojego Zbawiciela, który podobnte jak ziarno pszentcy rzucone $w$ glebe rozmnaza sie z jednego w wicle ziaren 1 dzlęki Bozemu błogosławleństwu nydaje kłos napeznlajłc swym plonem cały świat. Feniks, wspomnlany przez Euzeblusza na zasadzle taklego porównania, nle ma tu jednak charakteru wyłącznio chrześcijańgkiego, poniewaz z tradycja chrześcijariską łączy sie w dalszym citgu tej relacjl takze tradycja pogansko-cesarska.

Do. wyboru tekstón z literatury wczesnochrześc1jańskiej o feniksio, rypada jeszczo dodać diva eragmenty kazá́ $z \circ s \circ$ a mianowicle z Jego "Komentarza do Psalmu 118" 1 "H e k 3 a ne $r$ o $n$ un.

if plerwszy:a z nich przykładem feniksa ilustruje Ambrozy woralny obowlizek starania sie o czystośc 1 wstydliwośc/pudicitia/ na wó́r posteppowanla arabskiego ptaka: niẹ zna on stosunhón cieles-

13 Por. C.M.Edsaann, Phonix, RGG V 358.

14 Suscbius, Vita Constantini IV 72, PG 20, 1228, GCS $7,147 / \mathrm{lle} 1 \mathrm{kel} /$ 
nych, nie wie tez, co to sa lubiezne podniety zmysłowe, a ponstaje na nowo ze swego stosu: jako ptasl potomek dla siebie, jako pan wasnego clała 1 płód ze swego poploku 15 .

W drugim tekście Ambrozy podziela tradyoyjny pogląd przyjmowany przez większość starożytnych pisarzy o arabskim pochodzeniu reniksa $i$ o okresie 500 lat jego zycia. Pod kontec swego zycia ptak ten robl sobie schowek w postaci pokrywy/theca/ z kadzidła, mirry 1 innych pachnidel, wchodzi do niego w ostatnim momencie swego zycła 1 ublera. Z wilgoci jego ciała porstaje robak/vermis/, który dorasta 1 przekształca sie na nowo /reformatur/w dawna postać. Ptalk ten według Ambrozego'uczy nas swoin przykładem wlary w zmartwychwstanie/resurrectionem credere/. Ponlewaz ptak1 są dia człowieka, a nie człowiek dla ptaków, wioc 1 foniks powinien byó dla


nte pozioliz zginqzé temu jedyneau ptakowi, to jak mógt pozwolić, zeby na wieczność zginęld Jego swięc1. Wskazująo na przykład reniksa nawoływał Ambroźy kazdego ze swoich słuchaczy do zrobienia soble podobnego schowka w postaci pokrywy/theca/, tj. do zewleczenia z slebie starego człowieka wraz z jego uczynkami 1 wdziania na sieb1e nowego człowleka w przekonaniu, ze nasza pokrywą 1 osiona/theca, vagina/ jest Chrystus, Modl1ł s1e do Chrystusa, aby osłoniz 1 uicrył protagat et abscondat/ jego słuchaczy w nieszczéśliym dniu. Nasza osłonz/theca/, jest takze wara, która zaleca Ambrozy pypeznió kazdenu dobryai zapachami cnót, tj. czystości, miłosierdzia i sprawied11wości 16 .

if takiej oto alegorycznej interpretacj1 1 w oparciu o zasady homletyczne 1 moralne stosowal kaznodzleja mediolaxisk1 mit o penłksie, który był dla niego syinbolem zinartwychwstania Chrystusa 1 Jego wyznawców oraz symbolem wszelkiej odnowy, a zwłaszcza moralnej; ; podobny zreszta sposób interpretovali go jego poprzednicy w okresie literatury wczesnochrześcijaḱskiej.

$$
\text { K8. Henryk Wojtoricz - Lublin }
$$

15 Anbrosius, Expisitio in Psalgua 118, serao 19,13, PL 15, 1473 Ais. 16 Ambrostus, foxatacion V 23,79, CSEL 32/1,197, PSP $4,181$. 
DE AVE PHOENICE IN LITTEIIS PRIMAEVAE CHRISTIANITATIS ALlata /Argumentum/

Auctor de ave Phoenice apud antiquos scriptores christianos breviter narrat. Quae avis, auctoris opinione, a Clemente llomano, Tertulliano, Commodiano, Lactantio, Eusebio, Ambrosio resurrectionis et renascentiae signum affortur. 